\title{
De Onde Viemos? Uma Revisão Histórico-Conceitual da Psicoterapia de Casal
}

\author{
Terezinha Féres-Carneiro ${ }^{1}$ \\ Pontificia Universidade Católica do Rio de Janeiro \\ Orestes Diniz-Neto \\ Universidade Federal de Minas Gerais
}

\begin{abstract}
RESUMO - O objetivo deste trabalho é rever as principais tendências e mudanças, metodológicas e conceituais, da psicoterapia de casal, indicando a origem das abordagens e as mudanças na compreensão do objeto, métodos e modelos psicoterapêuticos. O foco metodológico foi construído a partir das revisões publicadas sobre a psicoterapia de casal, indexadas ao "PsycLit" e acessadas por meio do sítio da CAPES em agosto de 2006. Diferentes abordagens metodológicas e teóricas da psicoterapia de casal são descritas e vinculadas a diferentes períodos históricos. São apontadas contribuições recentes a partir de perspectivas feministas, transculturais e pós-modernas. Tentativas de articulações entre abordagens são também indicadas.
\end{abstract}

Palavras-chave: psicoterapia de casal; revisão histórica; metodologia; abordagens teóricas.

\section{Where do we come from? A Conceptual and Historical Review of Couple Psychotherapy}

\begin{abstract}
The purpose of the present paper is to review the main methodological and conceptual trends and changes of couple psychotherapy, indicating the approaches origin and changes in the understanding of the object, methodology, and psychotherapeutic models. The methodological focus was based on published couple psychotherapy review papers, presented in the PsycLit, and accessed trough CAPES home page in August, 2006. Diverse couple psychotherapy methodological and theoretical approaches are described and connected to several historical periods. Recent questions and contributions related to feminist, transcultural and post-modern perspectives are pointed out. Articulations among approaches are also indicated.
\end{abstract}

Keywords: couple psychotherapy; historical review; methodology; theoretical approaches.

O objetivo principal desta revisão é refletir sobre a construção do campo epistêmico da psicoterapia de casal. O campo da psicoterapia de casal desafia a possibilidade de uma revisão simples, pois muitas correntes, tendências e diferentes abordagens e perspectivas afloraram e conviveram em períodos históricos e em diferentes gerações de psicoterapeutas, simultaneamente. A evolução das abordagens, metodologias e teorias tampouco foi linear, o que impede uma descrição simples da história do campo. Tal fato se reflete, por exemplo, na escolha do uso dos termos "terapia de casal" e "psicoterapia de casal" pelos autores revisados. Embora o termo "psicoterapia de casal" pareça mais adequado, pela ênfase psicológica do tratamento, foi respeitada a escolha do uso de um ou outro termo pelos autores citados ao longo do texto. Portanto, realizar uma revisão teórica, ainda que sumária, parece útil, pois torna possível não só discernir os impasses teórico-metodológicos, mas também apontar direções possíveis de desenvolvimentos, indicando as principais e mais robustas descobertas do campo. Assim, ao traçar uma revisão conceitual sobre a terapia de casal serão abordados os seguintes aspectos: a orientação teórica dominante ou significativamente emergente em um período, o método adotado

1 Endereço: Rua General Góes Monteiro, 8, Bloco D/2403. Rio de Janeiro, RJ. CEP 22290-080.E-mail: teferca@puc-rio.br. e os autores significativos segundo as avaliações dos autores das revisões do referido campo. Foram consultadas revisões de psicoterapia de casal indexadas ao PsycLiT e acessadas por meio do sítio da $\mathrm{CAPES}^{2}$ em agosto de 2006.

\section{Um Esboço Histórico-Conceitual da Psicoterapia de Casal}

Todas as revisões apontam para as contribuições ocorridas no início do século XX, nos EUA, como significativas. Tal posição parece dever-se ao fato de a maior parte das escolas de psicoterapia de casal ter surgido, nos EUA, durante o século XX. Gurman e Fraenkel (2002) incluem, em sua revisão, o período do aconselhamento matrimonial que, por sua natureza peculiar, oferece campo para divergências como antecedente ou mesmo membro da tradição da psicoterapia de casal. Seguiremos o esquema de interpretação de Gurman e Fraenkel e Broderick e Schrader (1991), para os quais a história do aconselhamento matrimonial é a primeira fase, no sentido histórico, sendo a de menor contribuição teórica e metodológica, mas que respondeu, de maneira algo ingênua, à demanda por tratamento psicológico das relações conjugais.

2 www.capes.gov.br 


\section{Fases do Aconselhamento Matrimonial}

Broderick e Schrader (1991), ao traçarem a história do aconselhamento matrimonial, identificam quatro estágios. O primeiro, que vai de 1929 até 1932, denominado por eles de "estágio do pioneirismo", começa com a fundação dos três maiores institutos clínicos de aconselhamento matrimonial naquele período, embora já houvesse a prática pelo menos cinco anos antes. Nessa fase, predominava uma abordagem ateórica de profissionais de diferentes formações, guiados pelo "bom senso". Broderick e Schrader descrevem os primeiros conselheiros matrimoniais como um grupo mais ou menos ingênuo de profissionais, para os quais o aconselhamento matrimonial representava uma atividade auxiliar de sua principal profissão. Eram clérigos, médicos, educadores, que procuravam auxiliar, eminentemente de forma preventiva, os jovens casais a lidar com as dificuldades e ajustamentos da vida conjugal. $\mathrm{Na}$ maior parte das vezes, suas intervenções visavam ao esclarecimento das realidades biológicas, da vida a dois, além de fornecerem admoestações e conselhos sobre a necessidade de seguir os papéis conjugais, conforme o esperado pela sociedade. Não havia, de fato, nenhuma pretensão de ver esta atividade como ligada à área da saúde, nem tampouco a preocupação com a formação dos profissionais para lidar com problemas conjugais mais graves ou quadros psiquiátricos. A abordagem dos conselheiros era muito focal, de curto prazo e essencialmente pedagógica. $\mathrm{O}$ modelo clínico envolvia o atendimento ao casal, mas em sessões em separado, raramente ocorrendo atendimento conjunto ao casal (Barker, 1984).

O segundo período, compreendido entre 1934 e 1945, e denominado de "estágio do estabelecimento", foi marcado pela criação da American Association of Marriage Counselors - AAMC. A fundação de centros de treinamento e da AAMC tornou-se importante fator tanto para melhoria da formação, como da busca por maior reconhecimento profissional. No entanto, o modelo de atendimento permaneceu o mesmo. O terceiro período, entre 1946 e 1963, é considerado por Broderick e Schrader (1991) como o "estágio de consolidação", levando ao reconhecimento oficial da profissão de conselheiro matrimonial, em 1963. O quarto período, de 1964 a 1981, denominado de "estágio de formação", foi caracterizado pelo que L'Abate e MacHenry (1983) classificam como período de "intenso crescimento, clarificação de padrões e competências" (p. 3). Entretanto, Gurman e Fraenkel (2002) discordam quanto a considerar o término deste período em 1981, propondo, na revisão realizada em 2002, o término do mesmo em 1978. Esse seria marcado como o fim do termo "aconselhamento matrimonial", conforme assinalado pela mudança da então Americam Association for Marriage and Family Conseling (AAMFC) para Americam Association for Marriage and Family Therapy (AAMFT).

Do ponto de vista do formato do tratamento, o modelo de atendimento individual predominou até a década de sessenta. Michaelson (1963) estimava, a partir de relatos de casos de três centros de aconselhamento matrimonial, que nos anos quarenta, cerca de apenas $5 \%$ dos atendimentos ocorreram com a presença de ambos os cônjuges. Esse número sobe para $9 \%$ na década de cinqüenta e atinge $15 \%$ no início dos anos sessenta. Apenas no final da década de sessenta, a entrevista conjunta passou a ser predominante na prática clínica, aparentemente, pela influência de profissionais de outras formações que praticavam a terapia de casal (Gurman \& Fraenkel, 2002). O modelo de tratamento dominante do aconselhamento matrimonial sofria o que Olson (1970) classificou como séria ausência de princípios testados empiricamente. E, sem uma teorização derivada dessa fundamentação, não era possível operar na clínica de modo consistente. Broderick e Schrader (1991) notam ainda que, durante o período de predomínio da abordagem do aconselhamento matrimonial, havia uma ausência de compromisso com qualquer filosofia clínica em particular, o que levou Manus (1966) a declarar que "o aconselhamento matrimonial era simplesmente uma técnica em busca de uma teoria" (p. 449). Assim, durante esse período, a situação, do ponto de vista clínico, parecia oferecer uma grande dificuldade, pois de um lado ocorria um aumento significativo de demanda por atendimento a casais; por outro, havia uma ausência de teorização psicológica para fundamentar modelos que respondessem a essas demandas da prática clínica.

Alguns conselheiros matrimoniais buscaram a abordagem psicanalítica como resposta. Porém, esta era uma teoria que oferecia um modelo eminentemente individual, levando a conclusão de que "... se a terapia progride fatores inconscientes são descobertos... e o caso cessa de estar no campo do aconselhamento matrimonial" (Laidlaw, 1957, p. 56). Essa afirmativa revela o pouco espaço teórico e prático que existia para a clínica do aconselhamento matrimonial e também aponta para uma das questões que contribuiriam para a sua dissolução em 1978 (Gurman \& Fraenkel, 2002). Esses autores consideram compreensivo que o aconselhamento matrimonial tenha adquirido um traço psicanalítico, pois a terapia sistêmica de família estava, nos anos sessenta, ainda no berço e não ganhara credibilidade social. E, à medida que as relações conjugais tornavam-se objeto de estudo e emergiam intervenções cientificamente importantes, o grande grupo de profissionais ligados ao aconselhamento matrimonial perdia gradativamente prestígio e campo de atuação. Assim, após a segunda grande guerra, esses profissionais procuraram ligar-se ao mais prestigioso grupo de prática clínica que, nesse período, exercia a psicanálise.

Esse movimento apresentou, contudo, conseqüências imprevistas, pois o campo da terapia sistêmica de família, ao emergir, apesar de muitos de seus primeiros líderes e fundadores possuírem formação e treinamento formal em psicanálise, colocou-se em uma posição radicalmente crítica quanto à abordagem psicanalítica, questionando seu modelo e sua compreensão altamente individuais. Cabe notar que o aconselhamento matrimonial não produziu nenhum teórico de peso nos seus primeiros anos e, ao ligar-se ao movimento psicanalítico que declinava frente à emergência de outras abordagens da clinica da família e casal, desapareceu no final dos anos setenta. O mesmo não ocorreu com o pensamento psicanalítico que, embora tenha vivido um período de retraimento teórico e prático do campo de atendimento a casais, ressurgiu com importantes contribuições na década de oitenta (Gurman \& Fraenkel, 2002). 


\section{Contribuições da Psicanálise}

As contribuições do pensamento psicanalítico à psicoterapia de casal podem ser divididas em três períodos, segundo as tendências metodológicas e teóricas, e as contribuições técnicas (Gurman \& Fraenkel, 2002). O primeiro período vai da década de trinta até a década de sessenta, sendo caracterizado por experimentações e aplicação dos princípios e técnicas psicanalíticas tradicionais à situação de tratamento do casal. Ocorre, em um segundo período, que vai da metade da década de sessenta até a década de oitenta, um arrefecimento do interesse na aplicação da psicanálise à situação conjugal. Por um lado, devido às criticas do próprio movimento psicanalítico ao uso da psicanálise em situações não tradicionais, e, por outro, devido ao interesse despertado pelo movimento de terapia sistêmica de família, que formulou fortes críticas à abordagem psicanalítica, considerando-a excessivamente personalista e voltada ao intrapsíquico. Apenas a partir da década de oitenta observamos o aparecimento de um interesse renovado na abordagem psicanalítica de casais, caracterizando um novo período que se estende até os dias de hoje. No entanto, importantes contribuições foram feitas pelos pioneiros em suas tentativas de responder à demanda crescente de atendimento por parte dos casais.

As intervenções psicanalíticas com o casal desenvolveram-se de modo autônomo em relação ao aconselhamento matrimonial. É importante notar que, nos Estados Unidos no início do século XX, apenas psiquiatras eram admitidos como psicanalistas. Assim, um grupo de profissionais interessados em responder à demanda das dificuldades conjugais, incluindo problemas psiquiátricos, e insatisfeitos com os resultados do método analítico tradicional, iniciou uma série de experimentações e modificações na técnica, de um modo um pouco ambivalente. Aparentemente, a questão era: como tratar casais com uma técnica desenvolvida e voltada para o indivíduo?

A seleção do parceiro na formação do casal e os fatores que levavam à manutenção das relações conjugais, mesmo em situações de extremo estresse, já despertavam o interesse de psicanalistas nesse período. Oberndorf (1931, junho) apresentou um trabalho sobre a psicanálise de casais, descrevendo a relação das neuroses na formação do sintoma do casal. Anos depois, em 1938, Oberndorf publicou um artigo sobre psicanálise conjugal consecutiva, na qual a análise de um dos esposos começava quando terminava a do outro. Mittelman (1948) propôs outro enfoque ao descrever o tratamento conjugal como um processo de análise individual concomitante de ambos os esposos pelo mesmo analista. Essas abordagens despertaram, obviamente, críticas e restrições, pois contrariavam dramaticamente o método tradicional, no qual qualquer contato com qualquer membro da família deveria ser evitado, sob pena de "contaminação" da transferência (Greene, 1965). Mittelman foi ainda mais longe, ao realizar, segundo Sager (1966), a primeira sessão de casal conjunta na abordagem psicanalítica, motivado pela diferença nas histórias dos casais, que não combinavam em aspectos significativos. Embora essa intervenção tenha sido considerada, teoricamente, incorreta para a abordagem psicanalítica e, politicamente, incorreta para o período, revela a essência da hipótese que guiava a intervenção com casais: era tarefa do terapeuta destacar e corrigir as percepções distorcidas de ambos os cônjuges, permitindo uma relação liberta da irracionalidade. Assim, caberia ao analista decidir ou auxiliar na decisão do que era "mais racional". Mesmo Mittelman sentia-se ambivalente quanto a sessões conjuntas e acreditava que esse método só deveria ser usado em casos específicos, que atingiriam não mais que $20 \%$ das situações, e que os demais seriam mais beneficiados com análises em separado, com diferentes analistas.

Outras cautelosas experimentações ocorreram durante o final da década de cinqüenta e início da década de sessenta, mas, como nota Sager (1966), "estas contribuições não evidenciavam nenhum desenvolvimento significativo da teoria" (p. 460). De fato, envolviam propostas de diferentes formatos para psicoterapia, como a "terapia colaborativa", na qual dois analistas atendiam o casal, comunicando-se entre si sobre os processos em andamento, com o objetivo de manter o casamento (Martin, 1965). Tratamentos combinados também foram propostos com sessões conjuntas, com sessões individuais e de grupo, com vários propósitos e combinações (Greene, 1965). É importante notar que, nos métodos psicanalíticos de tratamento conjunto do casal, a visão individual prevalecia, embora desafiando a aderência aos métodos clássicos como a livre associação e a análise dos sonhos. A análise da transferência continuou como instrumento central do trabalho terapêutico, ampliada para incluir a transferência recíproca entre os cônjuges e a importância do "real" (Greene, 1965; Gurman \& Fraenkel, 2002).

Durante a década de sessenta ocorreu uma mudança na abordagem psicanalítica de casal, prevalecendo a realização de sessões conjuntas; no entanto, essa transição não foi feita sem ambivalência. Watson (1963), por exemplo, recomendava, em um artigo sobre o tratamento conjunto do casal, a realização de duas ou três sessões de anamnese com cada um dos cônjuges, antes da realização de sessões conjuntas. Tal prescrição seguia o pressuposto da necessidade do analista compreender o modo de conexão e sistema comunicativo do casal, bem como seus padrões de homeostase. Estes deveriam ser apreciados por meio de uma cuidadosa avaliação dos aspectos psicodinâmicos e desenvolvimentais de cada um dos cônjuges individualmente. A abordagem psicanalítica de casal começava a emergir, oferecendo hipóteses que orientaram o campo, como aponta Manus (1966): “A mais influente hipótese é que o conflito conjugal é baseado na interação neurótica dos parceiros... um produto da psicopatologia de um ou ambos os parceiros" (p. 449). Leslie (1964), em um artigo clássico dos anos sessenta, coloca que a técnica central do trabalho com casais era a identificação de distorções nas percepções mútuas dos parceiros, na transferência e contratransferência, e sua correção, permitindo a plena manifestação do conflito na sessão e sua direta alteração.

Mesmo com o aumento e a prevalência de métodos de abordagem conjunta do casal, a visão teórica e as técnicas terapêuticas permaneceram sem maiores mudanças. A ênfase ainda era na interpretação das defesas, que agora incluíam as defesas do casal além das individuais, no uso de técnicas de associação livre realizadas conjuntamente pelo casal e na análise dos sonhos, que agora incluía além das associações individuais, as associações do cônjuge (Gurman \& Fraenkel, 2002; Sager, 1967a). C. J. Sager, um dos mais influentes 
terapeutas de casal do período, ilustra bem essa ambivalência ao escrever: "Eu não estou envolvido primariamente em tratar desarmonias conjugais, que são um sintoma, mas em tratar os dois indivíduos no casamento" (Sager, 1967b, p. 185). Esse autor ainda se mantinha ligado à perspectiva tradicional psicanalítica, com forte ênfase nos processos de transações transferenciais trianguladas e na atenção aos elementos edípicos.

Essa ambivalência técnica refletia uma ambivalência teórica ainda maior para os psicanalistas do período: o lugar central daquilo que tradicionalmente seria o caráter distintivo da psicanálise, ou seja, a análise da transferência. Skynner (1980), ao avaliar a produção do período, uma década mais tarde, influenciado pela escola das relações objetais, nota que a abordagem psicodinâmica parecia ter perdido o seu caminho na identificação das técnicas indutoras de mudança do casal, ao focar de modo inapropriado o conceito de transferência e as técnicas interpretativas. Retrospectivamente notou que, na abordagem psicanalítica de casal, os conflitos inconscientes deveriam ser considerados presentes e totalmente desenvolvidos em padrões projetivos. E que esses poderiam ser mais bem trabalhados diretamente do que por meio de métodos indiretos como a interpretação da transferência.

A ambivalência em relação ao núcleo central da teoria psicanalítica parecia não oferecer, no final da década de sessenta, uma saída simples para o impasse teórico e técnico, levando a uma diminuição temporária do interesse pela abordagem psicanalítica. Essa sofreu, ainda na década de sessenta, fortes críticas das escolas de terapia de família, que começavam a expandir o seu movimento. Como notam Broderick e Schrader (1991), o artigo de Sager (1966) sobre uma revisão histórica do desenvolvimento da psicoterapia de casal de orientação psicanalítica "parece ser o verdadeiro zênite de seu desenvolvimento independente" (p. 17) no período. A ausência de desenvolvimentos teóricos e técnicos próprios e as fortes críticas, tanto da psicanálise mais ortodoxa como da abordagem da terapia de família, levaram a um período de declínio do interesse na terapia psicanalítica de casais. Apenas na década de oitenta, com importantes mudanças teóricas e novas metodologias, surgiu um novo interesse na aplicação do enfoque psicanalítico à clínica da conjugalidade (Gurman \& Fraenkel, 2002).

\section{Contribuições da Terapia de Família à Psicoterapia de Casal}

Durante as décadas de cinqüenta e sessenta, outro paradigma desenvolveu-se a partir de estudos, reflexões e novas descobertas que colocavam novos enfoques sobre a questão das "patologias psicológicas" (Diniz-Neto \& Féres-Carneiro, 2005a, 2005b, 2005c). Estudos pioneiros parecem ter se inspirado no, hoje, clássico estudo intitulado Toward a theory of esquizofreny, de Bateson, Jackson, Haley e Weakland (1956), no qual esses autores apresentaram pela primeira vez a teoria do duplo vínculo, apontando para a possibilidade e necessidade de intervenções, não com o indivíduo como membro, mas com a família como campo de tratamento (Féres-Carneiro, 1996; Ferro-Bucher, 1989, 1990; Foley, 1984/1995). É curioso notar que muitos dos pioneiros da terapia de família, como Akerman, Jackson, Framo e Bowen, dentre outros, tinham sólida formação em psicanálise (Ferro-Bucher, 1989,1990; Féres-Carneiro, 1996; Foley, 1984/1995). No entanto, apesar de muitos autores, hoje em dia, integrarem criativamente conceitos psicodinâmicos e sistêmicos em larga medida, a história inicial da terapia sistêmica de família foi marcada por uma forte e, às vezes, radical discordância de muitos dos princípios aceitos da psicoterapia psicanalítica e psicodinâmica, em especial, do foco nos aspectos psicodinâmicos individuais como princípios teóricos explicativos e de intervenção. Essas fortes críticas somadas ao interesse pela abordagem da família, e não mais do casal, juntamente com os impasses teóricos, levaram a um esmaecimento da abordagem psicanalítica de casal. Não se tratou de fato de um desaparecimento, pois apesar de sua menor visibilidade em termos de publicações, ocorreram algumas significativas contribuições como as de Framo (1976, 1981), Paul (1969) e Sander (1979). O pensamento psicanalítico não desapareceu, mas ficou fragmentado e marginalizado pelas escolas de terapia dominantes no período.

Revendo a história do campo da psicoterapia, talvez o evento de maior impacto, desde o desenvolvimento da psicanálise, seja o aparecimento do que, na época, por questionar radicalmente seus pressupostos, pareceu ser o seu maior contraponto: a terapia sistêmica de família (Diniz-Neto \& Féres-Carneiro, 2005c). Como nota Fraenkel (1997): “As abordagens sistêmicas desenvolveram-se em larga medida como uma reação às limitações percebidas nas terapias que atribuíam as disfunções psicológicas e sociais a apenas problemas no individual, fosse este visto como de natureza biológica, psicológica, psicodinâmica ou comportamental"' (p. 380).

Porém, historiadores do período descrevem o seu surgimento como resultado, também, de uma absorção do campo da psicoterapia de casal pela abordagem sistêmica de família. Broderick e Schrader (1991) referem-se a "uma mistura ou amálgama das abordagens" (p. 15). Nichols e Schwartz (1998) referem-se à "terapia de família absorvendo a psicoterapia de casal" (p. 37). Olson, Russel e Sprenkle (1980) concluem que "no início da década de oitenta a distinção entre terapia de família e psicoterapia de casal havia desaparecido" (p. 973), notando ainda que o campo havia se tornado "unitário, mas não totalmente unificado e integrado" (p. 973). Essa situação é o reflexo da diferença conceitual e metodológica que separava ambos os campos e que marcou a evolução histórica de ambas as abordagens. Haley (1984) afirma que o "aconselhamento matrimonial não parece ser relevante para o desenvolvimento do campo da terapia de família" (p. 5), apontando, ainda, o que pode ser visto como a dinâmica do campo, no período, quando observa que "não houve uma única escola de terapia de família que se originasse do grupo das escolas de aconselhamento matrimonial" (p. 6).

Essas críticas endereçam-se a duas características marcantes do campo do aconselhamento matrimonial, e que se tornaram fatais no desenvolvimento dessa abordagem. A primeira refere-se ao fato de que o aconselhamento matrimonial não desenvolveu abordagens próprias durante mais de quarenta anos, e a segunda, ao fato de ter realizado apenas assimilações de outros campos, como o da psicoterapia psicanalítica de casais. Como coloca Haley (1984), “conselheiros matrimoniais adotavam idéias de outras terapias. Quando a terapia 
individual era psicodinâmica, o aconselhamento matrimonial tendia a propor estas idéias" (p. 7). Idéias essas que foram duramente atacadas pelo movimento de terapia sistêmica de família. $\mathrm{O}$ foco também parecia deslocado da inclusão da família como um todo e qualquer proposta de atender menos que a família parecia inadequada ou insuficiente. Isso não quer dizer que os teóricos pioneiros da terapia sistêmica de família não tivessem nenhuma contribuição ou interesse nas questões conjugais. É possível apontar, como Gurman e Fraenkel (2002) o fizeram, algumas contribuições seminais, de autores como Donald Jackson, Jay Haley, Virginia Satir, e Murray Bowen, todas significativas para a prática e teoria da terapia com casais.

Durante a metade da década de sessenta, a década de setenta e início da década de oitenta, a abordagem sistêmica da família moldou a visão de tratamento de distúrbios psicológicos que incluíam aspectos conjugais. Todo tratamento conjugal deveria passar pela visão da família. Tratar algo menos que a família era considerado inadequado. Essa perspectiva esteve presente nas diversas escolas de terapia de família e moldou grande parte da produção do campo. Isso pode ser inferido de alguns desdobramentos. Em primeiro lugar, o aconselhamento matrimonial, em que ainda pese a sua ausência de contribuições teóricas e técnicas significativas, acabou sendo absorvido teoricamente pelo movimento da terapia de família, o que levou ao seu fim enquanto profissão em 1979. Por outro lado, no campo da terapia de casal psicanalítica, seus praticantes debatiam-se no dilema de manterem-se fiel à teoria e à técnica psicanalítica ou lançarem-se na criação e desenvolvimento de teorias e técnicas para além do intrapsíquico, envolvendo o inter-relacional, correndo um risco de uma certa imobilização. Apareceram poucos avanços teóricos nessa escola, sendo os mais notáveis referentes às contribuições de Dicks (1967), no clássico Marital Tensions, que se tornou o livro texto da abordagem da teoria das relações objetais na relação conjugal. São também relevantes os trabalhos de Sager $(1976,1981)$ sobre o "contrato conjugal" e a contribuição original de Framo $(1965,1996)$, que desenvolveu modelos de atendimento a casais em grupo, e em sessões com a família de origem, orientado pela teoria das relações objetais. As abordagens experienciais humanísticas, originadas das contribuições de Virginia Satir, encontraram-se marginalizadas até meados da década de oitenta, na medida em que a própria Virginia Satir afastou-se do movimento de terapia de família. Assim, Gurman e Fraenkel (2002) consideram que nesse período, da metade da década de sessenta à metade da década de oitenta, poucos trabalhos de monta surgiram no campo da terapia de casal, indicando um eclipse da abordagem. Porém, o interesse no campo não desapareceu por completo. Nas décadas de setenta e oitenta, pesquisas sobre a eficácia da psicoterapia em geral emergiram, recolocando questões sobre a validade de abordagens teóricas e métodos de tratamento, e levando a um renovado interesse no campo.

Em 1986, Jacobson e Gurman publicaram o clássico Clínical Handbook of Marital Therapy, anunciando, pela sua grande difusão e utilização, o quarto período do desenvolvimento conceitual da psicoterapia de casal. Esse período conceitual do desenvolvimento da psicoterapia de casal foi marcado pelo aumento de sólidas pesquisas empíricas sobre a conjugalidade, o exame detalhado de conceitos e teorias até então propostas, o aparecimento de pesquisas empíricas experimentais sobre modelos e a criação de centros de pesquisa e treinamento de terapeutas de casal. A combinação desses fatores levou a um contínuo refinamento, à colocação de novas questões e críticas e ao desenvolvimento de abordagens e modelos durante o período.

\section{Críticas e o Desenvolvimento de Novas Abordagens}

Nas diversas revisões abordadas, os autores concordam que, durante a década de setenta e início da década de oitenta, importantes desenvolvimentos críticos foram realizados em um contexto mais amplo, mas com profundas repercussões sobre o campo da psicoterapia de casal. Pelo menos três importantes aspectos do conhecimento foram fortemente questionados, levantando importantes questões sobre a teoria e prática da psicoterapia de casal. E, embora cada um destes aspectos apontasse para diferentes perspectivas, todos questionaram pressupostos que, até então, orientavam de forma inconsciente muitas das produções no campo da psicoterapia de casal.

O movimento feminista revelou pontos críticos do pensamento científico, ao identificar seus pressupostos falocêntrico e patriarcal. A expansão do olhar da produção científica sobre a conjugalidade, para além dos padrões da sociedade ocidental judaico-cristã, revelou novos aspectos sobre a conjugalidade presentes nas diferentes culturas, descortinando importantes questões. E, ainda, o chamado pós-modernismo, com sua crítica sobre os aspectos fundacionais do conhecimento, apontou novas direções de inquirição, envolvendo profundamente o pesquisador e o contexto da produção científica. Em conjunto, cada qual a seu modo, essas linhas de questionamento imprimiram novas direções na pesquisa, no pensar sobre a conjugalidade e no tratamento de suas demandas.

A visão crítica do feminismo, com o estudo das dimensões, socialmente construídas, das diferenças entre gêneros, levou à compreensão de que as crenças estabelecidas sobre a diferenciação de papéis na sociedade ocidental ocultavam aspectos históricos de expectativas implícitas e explícitas de pressões sociais. Assim, as crenças sobre a construção de complementaridades dos papéis entre parceiros, em uma relação conjugal, foram desafiadas, revelando preconceitos enraizados que atravessavam não só muitas das leituras teóricas, mas também intervenções na prática clínica da psicoterapia de casal. Goldner (1985) ilustra esse ponto ao afirmar que; “(...) a complementaridade conjugal deve ser entendida como não apenas um arranjo psicológico entre marido e esposa, mas também... estruturando relações íntimas no contexto mais amplo das relações sociais" (p. 31).

Além disto, Goldner (1985) colocou em relevo que essa prescrição, além de aumentar a rígida complementaridade em gerações de funcionamento de famílias e casais, acentuou, prescritivamente, produções de subjetividades cindidas ou, pelo menos, com desenvolvimento parciais. Pensadores sistêmicos, até esse período, ao participarem socialmente dessa crença, negligenciaram a hierarquia de gêneros, situando-a em uma hierarquia transgeracional, em suas construções teóricas e intervenções, compactuando, assim, para manutenção desse status quo. Outro foco de crítica foi o uso do conceito 
de circularidade nas relações de casal que supunha uma coparticipação na emergência e manutenção de situações de constrangimento, intimidação e violência, nas quais, muitas vezes, as mulheres eram vítimas, deixando uma conotação de que não só ambas as partes eram responsáveis igualmente pela situação de violência, como também que as mulheres eram responsáveis pela manutenção de sua condição de vítimas (Avis, 1992).

A crítica feminista, como preconizada pelo Akerman Violence Project (Goldner, Penn, Sheinberg \& Walker, 1990), coloca que a construção de teorias circulares, como proposta pela perspectiva sistêmica, serve também como manutenção de uma descrição socialmente construída. A visão linear de causalidade, nos casos em que homens são os responsáveis únicos pela violência contra as mulheres, oferece outra perspectiva possível, moralmente comprometida com a proteção das vítimas. Assim, esses autores apontam que, enquanto seres sociais, escolhemos quando e quais teorias, pelo menos no campo das ciências humanas, usaremos para abordar e ressaltar um aspecto da realidade e, ainda, que sentido construiremos. Portanto, consideram que a escolha teórica implica uma responsabilidade moral, por convidar a uma praxis social. Além dessas críticas à concepção sistêmica do funcionamento do casal e da família, as feministas notaram que a terapia é construída por estereótipos de gênero. Hare-Mustin (1978) aponta para os padrões paternalísticos da hierarquia do relacionamento terapeuta-cliente, com o terapeuta, deliberadamente ou não, reforçando o papel estereotipado de comportamento, como nos modelos de terapias focadas na solução de problemas do casal.

Goldner e cols. (1990) notam, ainda, a posição paradoxal da mulher no campo da terapia de casal que, ao funcionar como monitor do bem-estar emocional do casal, sinaliza ao marido a necessidade de buscar ajuda e, geralmente, é quem telefona para marcar a primeira sessão. Contudo, a esposa, uma vez em terapia, alia-se ao terapeuta para manter o casal em terapia e, simultaneamente, inibe a terapia ao evitar críticas ao marido, o qual sinaliza o uso do seu poder de veto caso não goste do que escutar. Essa situação caracteriza-se como típica do exercício de poder e introduz a esposa em uma situação paradoxal. Papp (2000), a partir dessas críticas, desenvolveu diversas técnicas para trabalhar e romper com as crenças limitadoras de gêneros. Da mesma forma que outras críticas à terapia de casal como, por exemplo, o multiculturalismo, o feminismo desafia crenças e estereótipos relacionados com a distribuição de parcerias no cuidado com os filhos e com a distribuição de tarefas como cuidados com a casa, o lar e o trabalho fora de casa. Goldner (1985) nota que embora exista uma vasta literatura feminista no campo da história, da psicanálise e da sociologia, a produção de obras com críticas feministas ao casal e à família emerge, curiosamente, quando as autoras feministas experimentam a transformação da maternidade em suas vidas e seus paradoxos na nossa cultura. Tipicamente, o nascimento do primeiro filho, em nossa cultura, faz emergir de modo inegável as diferenças sociais e culturais dos estereótipos e papéis do homem e da mulher. Tal situação não pode ser naturalizada e, mesmo em uma época de múltiplas experiências em formas de conjugalidade e famílias, estudos como os de Gottman $(1991,1994)$ têm demonstrado que o impacto da divisão de trabalho doméstico na vida do casal influencia não só o nível de bem-estar e satisfação conjugal, mas, até mesmo, o nível de longevidade (Apter, 1985; Bernard, 1982). De fato, ao desafiar as crenças e preconceitos sobre o relacionamento conjugal e parental nas famílias, o movimento feminista revelou importantes aspectos das dificuldades maritais que se referem às diferentes maneiras como os dois membros de um casal heterossexual experimentam e acessam os limites de poder e de diferentes expectativas quanto à intimidade (Gurman \& Fraenkel, 2002).

Ao mesmo tempo em que o campo da psicoterapia de casal recebia críticas do movimento feminista, ocorria o reconhecimento da importância da diversidade das experiências dos casais, em função das diferenças sociais, econômicas, étnicas e geográficas. Ainda, essas diferenças não poderiam ser simplesmente compreendidas como desvios dos padrões normais, isto é, socialmente dominantes (Gurman \& Fraenkel, 2002). Com exceção dos trabalhos sobre casais homossexuais e sobre a perspectiva feminista, a maior parte dos estudos sobre aspectos multiculturais está expressa em obras gerais de estudos sobre famílias. Até o presente, existem poucos trabalhos específicos sobre essas importantes questões, destacando-se os de Black (2000), Fraenkel e Wilson (2000), Mohr (2000) e Perel (2000).

Resumidamente, dois pontos principais são enfatizados nesses trabalhos. Primeiramente, as normas referentes à qualidade e à quantidade de intimidade, à distribuição de poder entre os cônjuges, ao grau de envolvimento de outras pessoas na intimidade do casal (família, amigos, amantes) e a outros aspectos nucleares da vida do casal, variam de acordo com as etnias, grupos sociais, classes econômicas e orientações sexuais, dentre outras afiliações e identificações psicossociais. Em segundo lugar, dependendo da posição de cada grupo dentro do contexto social mais amplo, a afiliação e identificação psicossocial provêm privilégios e dificuldades às condições de vida, e opressão social. E é evidente que esses fatores influenciam tanto o processo do relacionamento do casal como a satisfação conjugal. Assim, uma vez que o casal e cada um dos seus participantes estão imersos nessa teia político-econômico-social, torna-se importante levar em conta a construção de um contexto compreensivo da experiência conjugal, que será significada e marcada por essas questões. Para o contexto brasileiro, a observação de Boyd-Franklin (1993) feita para a sociedade norte americana mostra-se pertinente e pode ser aplicada: “... para as famílias afroamericanas habitantes das cidades, a realidade do dia-a-dia, com o racismo, a discriminação, o classicismo, a pobreza, a violência, o crime e as drogas criam forças que continuamente ameaçam a sobrevivência da família” (p. 361).

Gurman e Fraenkel (2002) notam que a emergência da perspectiva multicultural possui implicações de longo alcance, tanto para a teorização como para a prática clínica, e que tais questões encontram-se ainda muito pouco exploradas. De forma semelhante às questões de gênero apontadas pelo movimento feminista, o impacto das diferenças socioculturais que acompanham o papel do terapeuta, com suas afiliações e privilégios, marca de forma inevitável as teorizações, crenças e intervenções terapêuticas. As identificações socioculturais, étnicas, econômicas e políticas do terapeuta provêem uma base para o viés de sua leitura, construção de experiências e 
intervenções que podem estar marcadas pela reprodução de uma política de manutenção de privilégios e poder de classe, afetando todo o processo terapêutico: da formação da aliança terapêutica até a construção e realização de intervenções.

É importante assinalar que cada casal deve ser visto como uma combinação única de condições socioculturais e, assim, a perspectiva multicultural parece requerer do terapeuta uma abordagem mais colaborativa, mais etnográfica e antropológica, na qual ele deve investigar o contexto dos valores e expectativas que caracterizam as culturas dos membros do casal e, conseqüentemente, o significado particular de seus problemas e do que seria um estado "adequado". A flexibilidade, na construção hierárquica em um contexto de terapia, é um ponto crítico, principalmente quando a raça e o nível sócio-econômico e cultural colocam o terapeuta em uma aparente posição superior, de poder e de saber, no encontro terapêutico. Cabe ressaltar que proficiência e hierarquia não são inerentemente atitudes antiéticas, pois podem ser utilizadas em um encontro colaborativo e respeitoso sobre as diferenças. A hierarquia deve ser vista como funcional no momento do encontro terapêutico e não transpor padrões de relacionamento socialmente marcados, construindo subjetividades restringidas. A dimensão cultural, assim, tem ganhado destaque, desde a década de 1980, como um dos desdobramentos teóricos mais significativos dentro do campo da psicoterapia em geral e também da psicoterapia de casal.

Desde a década de oitenta, o campo da ciência e o da psicoterapia tem recebido forte impacto das críticas pósmodernas, em especial, do construtivismo (Watzlawick, 1981/1994), do construcionismo social (Anderson \& Goolishian, 1988; Gergen, 1998), das teorias de solução de problemas (White \& Epston, 1991) e de abordagens derivadas desses enfoques. De modo sucinto, pode-se dizer que o pós-modernismo critica o realismo, isto é, a crença em uma realidade objetiva, que poderia ser conhecida, sem referência ao observador, por meio do método científico. Propõe, como alternativa, um conceito da realidade socialmente construída, relativa ao contexto social e histórico do conhecedor. Essa nova epistemologia resultou em inúmeras mudanças no campo da terapia sistêmica familiar e, também, da psicoterapia de casal. Entre elas, algumas se destacam. A primeira seria a mudança do terapeuta de especialista para colaborador na investigação do casal sobre o significado de suas dificuldades e possibilidades de solução. Ocorreu, também, uma modificação da descrição das interações do casal: o interesse em seqüências comportamentais e cibernéticas foi substituído pelo interesse na compreensão da construção de significados articulados. Isso levou a uma busca da compreensão de como a linguagem do casal é usada para descrever as dificuldades do relacionamento, não só qualificando os problemas, mas também delimitando as possibilidades de solução. Esse deslocamento colocou uma ênfase no aspecto único de cada situação clínica e do significado singular de cada experiência. Essa nova abordagem tem auxiliado os casais a perceber como o impacto de certa descrição problematiza e limita suas ações. Possibilita, portanto, que se desidentifiquem dessas descrições, criando novas alternativas de experiências criativas, desafiando crenças limitadoras derivadas das ideologias dominantes e fundacionais. Essa desconstrução de significados convida à construção de novos significados para a identidade nuclear do casal, levando à oportunidade de mudança e renovação.

Deve-se notar que embora as teorias pós-modernas tenham, como as teorias feministas e multiculturais, surgido de críticas aos valores e imposições presentes nas grandes narrativas que expressariam meios de controle e opressão, diferem destas ao considerar a inexistência de uma realidade objetiva, que estaria apenas mascarada por ideologias dominantes cuja finalidade seria manter seus interesses. As teorias pós-modernas enfatizam a relatividade de toda e qualquer narrativa as quais trariam conseqüências sociais, políticas e econômicas. Como conseqüência, as teorias feministas e multiculturais experimentam pontos de conflito e resistência com as perspectivas pós-modernas (Hare-Mustin \& Marecek, 1994).

\section{Considerações Finais}

A construção da identidade da psicoterapia de casal tem sido longa, refletindo diversos paradigmas, forças sociais, políticas e econômicas. Embora seja inegável a importância da abordagem psicológica na compreensão da conjugalidade e de suas disfunções, muito se pode esperar nos próximos anos de seu desenvolvimento. Assim, o campo da psicoterapia de casal apresenta atualmente um quadro referencial plural em seu olhar, caracterizado pelo diálogo e articulação de modelos (Gurman e Fraenkel, 2002; Diniz-Neto \& FéresCarneiro, 2005a). A questão de aderência teórica rígida tem dado lugar à discussão sobre eficácia e eficiência terapêutica, na busca de validação de modelos apropriados a questões específicas, dentro da discussão de uma ética do tratamento. E quaisquer que sejam esses desdobramentos, com suas convergências e divergências, as perspectivas do feminismo, do multiculturalismo e do pós-modernismo trouxeram uma aguda consciência da diversidade de experiências de homens e mulheres de diferentes culturas (Gurman \& Fraenkel, 2002). Em conjunto, essas críticas aos padrões da psicoterapia de casal não só influenciaram como têm refletido os desenvolvimentos posteriores no campo (Diniz-Neto \& Féres-Carneiro, 2005a, 2005b), gerando novas formas de abordar e tratar a conjugalidade, conscientizando-nos de nossa responsabilidade e de nosso lugar na compreensão da co-produção de novas formas de conjugalidade daqueles que são nossos parceiros, ou seja, nossos clientes.

\section{Referências}

Anderson, H. \& Goolishian, H. (1988). Human systems as linguistic systems: Preliminary and evolving ideas about the implications for clinical theory. Family Process, 27, 371-393.

Apter, T. (1985). Why women don't have wife? New York: Schocken.

Avis, J. M. (1992). Where are all the family therapists? Abuse and violence within families and family therapy's response. Journal of Marital and Family Therapy, 18, 223-230.

Barker, R. L. (1984). Treating couples in crisis. New York: The Free Press.

Bateson, G., Jackson, D., Haley, J. \& Weakland, J. (1956). Toward a theory of schizophrenia. Behavioral Science (Michigan), $1,251-264$. 
Bernard, J. S. (1982). The future of marriage. New Haven: Yale University Press.

Black, L. W. (2000). Therapy with african-american couples. Em P. Papp (Org.), Couples on the fault line: New directions for therapists (pp. 205-221). New York: Guilford.

Boyd-Franklin, N. (1993). Race, class and poverty. Em F. Walsh (Org.), Normal family processes (pp. 361-376). New York: Guilford.

Broderick, C. B. \& Schrader, S. S. (1991). The history of professional marriage and family therapy. Em A. S. Gurman \& D. P. Kniskern (Orgs.), Handbook of family therapy, Vol. 2 (pp. 3-40). New York: Brunner/Mazel.

Dicks, H. V. (1967). Marital tensions. New York: Basic Books.

Diniz-Neto, O. \& Féres-Carneiro, T. (2005a). Eficácia psicoterapêutica: terapia de família e o efeito Dodô. Estudos de Psicologia (Natal), 10, 355-361.

Diniz-Neto, O. \& Féres-Carneiro, T. (2005b). Psicoterapia de casal na pós-modernidade: rupturas e possibilidades. Estudos de Psicologia (Campinas), 22, 133-141.

Diniz-Neto, O. \& Féres-Carneiro, T. (2005c) Vida conjugal, família e trabalho. Em A. Hounie \& W. Camargos (Orgs.), Manual dos transtornos de décifit de atenção (pp. 546-596). Belo Horizonte: Editora Info.

Féres-Carneiro, T. (1996). Família: diagnóstico e terapia. Petrópolis: Vozes.

Ferro-Bucher, J. S. N. (1989). Terapia familiar: su enseñanza y investigación en el contexto brasileño. Revista Interamericana de Psicologia, 23, 33-51.

Ferro-Bucher, J. S. N. (1990). Dos estudos da família à terapia familiar no Brasil. Psicologia: Reflexão e Crítica, 3, 43-58.

Foley, V. (1995). Introdução à Terapia Familiar. (J. O. A. Abreu, Trad.) Porto Alegre: Artes Médicas. (Trabalho original publicado em 1984)

Fraenkel, P. (1997). Systems approaches to couple therapy. Em W. K. Halford \& H. J. Markman (Orgs.), Clinical handbook of marriage and couples interventions (pp. 379-414). New York: John Wiley e Sons.

Fraenkel, P. \& Wilson, S. (2000). Clocks, calendars, and couples: Time and the rhythms of relationships. Em P. Papp (Org.), Couples on the fault line: New directions for therapists (63103). New York: Guilford.

Framo, J. L. (1965). Rationale and techniques of intensive family therapy. Em I. Boszormenyi-Nagy \& J. L. Framo (Orgs.), Intensive family therapy (pp. 143-212). New York: Harper and Row.

Framo, J. L. (1976). Family of origin as a therapeutic resource for adults in marital and family therapy: You can and should go home again. Family Process, 15, 193-210.

Framo, J. L. (1981). The integration of marital therapy with sessions with family of origin. Em A. S. Gurman \& D. P. Kniskern (Orgs.), Handbook of family therapy (pp. 133-158). New York: Brunner/Mazel.

Framo, J. L. (1996). A personal retrospective of the family therapy field: Then and now. Journal of Marital and Family Therapy, 22, 289-316.

Gergen K. J. (1998). The ordinary, the original and believable in psychology's construction of the person. Em B. M. Bayer \& J. Shotter(Orgs.), Reconstructing the psychological subject: Bodies, practices and technologies (pp. 111-125). London: Sage.
Goldner, V. (1985). Feminism and family therapy. Family Process, 24, 31-47.

Goldner, V., Penn, P., Sheinberg, M. \& Walker, G. (1990). Love and violence: Gender paradoxes in volatile attachments. Family Process, 29, 343-364.

Gottman, J. M. (1991). Predicting the longitudinal courses of marriage. Journal of Marital and Family Therapy, 17, 3-7.

Gottman, J. M. (1994). What predicts divorce? Hillsdale: Lawrence Erlbaum.

Greene, B. L. (1965). Introduction: A multioperational approach to marital problems. Em B. L. Greene (Org.), The psychotherapies of marital disharmony (pp. 1-14). New York: The Free Press.

Gurman, A. S. \& Fraenkel, P. (2002). The history of couple therapy: A millennial review. Family Process, 41, 199-260.

Haley, J. (1984). Marriage or family therapy. American Journal of Family Therapy, 12, 3-14.

Hare-Mustin, R. T. (1978). A feminist approach to family therapy. Family Process, 17, 181-194.

Hare-Mustin, R. T. \& Marecek, J. (1994). Feminism and postmodernism: Dilemmas and points of resistance. Dulwich Centre Newsletter, 4, 13-19.

Jacobson, N. S. \& Gurman, A. S. (1986). Clinical handbook of couple therapy. New York: Guilford.

L'Abate, L. \& MacHenry, S. (1983). Handbook of marital interventions. New York: Grune and Stratton.

Laidlaw, R. W. (1957). The psychiatrist as marriage counselor. Em C. E. Vincent (Org.), Readings in marriage counseling (pp. 52-61). New York: Crowell.

Leslie, G. R. (1964). Conjoint therapy in marriage counseling. Journal of Marriage and the Family, 26, 65-71.

Manus, G. I. (1966). Marriage counseling: A technique in search of a theory. Journal of Marriage and the Family, 28, 449-453.

Martin, P.A.(1965). Treatment of marital disharmony by collaborative therapy. Em B. L. Greene (Org.), The psychotherapies of marital disharmony (pp. 83-102). New York: The Free Press.

Michaelson, R. (1963). An analysis of the changing focus of marriage counseling. Doctoral Dissertation, University of Southern California, Los Angeles, California, United States of America.

Mittelman, B. (1948). The concurrent analysis of married couples. Psychiatric Quarterly, 17, 182-197.

Mohr, R. (2000). Reflections on Golden Pond. Em P. Papp (Org.), Couples on the fault line: New directions for therapists (pp.321334). New York: Guilford.

Nichols, M. P. \& Schwartz, R. C. (1998). Family therapy: Concepts and methods. Boston: Allyn and Bacon.

Oberndorf, C. P. (1931, junho). Psychoanalysis of married couples. Trabalho apresentado no $87^{\circ}$ Congresso da American Psychiatric Association, Toronto, Ontário, Canadá.

Oberndorf, C. P. (1938). Psychoanalysis of married couples. Psychoanalytic Review, 25, 453-475.

Olson, D. H. (1970). Marital and family therapy: Integrative review and critique. Journal of Marriage and Family, 32, 501-538.

Olson, D. H., Russell, R. C. \& Sprenkle, D. H. (1980). Marital and family therapy: A decade review. Journal of Marriage and Family, 42, 973-992.

Papp, P. (2000). Gender differences in depression: His or her depression. Em P. Papp (Org.), Couples on the fault line: New directions for therapists (pp. 130-151). New York: Guilford. 
Paul, N. (1969). The role of mourning and empathy in conjoint marital therapy. Em G. Zuk \& I. Boszormenyi-Nagy (Orgs.), Family therapy and disturbed families (pp.186-205). Palo Alto: Science and Behavior Books.

Perel, E. (2000). A tourist's view of marriage: Cross-cultural couples-challenges, choices and implications for therapy. Em P. Papp (Org.), Couples on the fault line: New directions for therapists (pp. 178-204). New York: Guilford.

Sager, C. J. (1966). The development of marriage therapy: An historical review. American Journal of Orthopsychiatry, 36, 458-467.

Sager, C. J. (1967a). The conjoint session in marriage therapy. American Journal of Psychoanalysis, 27, 139-146.

Sager, C. J. (1967b). Transference in conjoint treatment of married couples. Archives of General Psychiatry, 16, 185-193

Sager, C. J. (1976). Marriage contracts and couple therapy. New York: Brunner/Mazel

Sager, C. J. (1981). Couples therapy and marriage contracts. Em A. S. Gurman \& D. P. Kniskern (Orgs.), Handbook of family therapy (pp. 85-130). New York: Brunner/Mazel.
Sander, F. M. (1979). Individual and family therapy: Toward an integration. New York: Jason Aronson.

Skynner, A. C. (1980). Recent developments in marital therapy. Journal of Family Therapy, 2, 271-296.

Watson, A. S. (1963). The conjoint psychotherapy of married partners. American Journal of Orthopsychiatry, 33, 912-922.

Watzlawick, P. (1994). Prefácio. Em P. Watzlawick (Org.) A realidade inventada. (J. P. dos Santos, Trad.) Campinas: Psy. (Trabalho original publicado em 1981)

White, M. \& Epston, D. (1991). Narrative means to therapeutic ends. New York: Norton.

Recebido em 19.04.2007

Primeira decisão editorial em 18.03.2008

Versão final em 03.10.2008 